Check for updates

Cite this: RSC Adv., 2019, 9, 13243

Received 20th March 2019

Accepted 16th April 2019

DOI: $10.1039 / c 9 r a 02169 h$

rsc.li/rsc-advances

\section{Design and synthesis of Co"HMTAA-14/16 macrocycles and their nano-composites for oxygen reduction electrocatalysis $\uparrow$}

\begin{abstract}
Anuj Kumar ${ }^{a}$ and Vinod Kumar Vashistha (iD *b
The major concerns in the design of macrocycle based-ORR catalysts are: (i) understanding the macrocyclic, $\pi$-conjugation, central metal and substituent effects on ORR electrocatalysis; and (ii) the use of macrocycles on the electrode surface for the retention of ORR activity because of their poor stability. In this work, we demonstrated the aromaticity/ $\pi$-electron conjugation effect on ORR activity by using the same macrocycles [HMTAA-14 and 16 (hexamethyltetraaza [14] and [16] annulenes)] with a difference in their macrocyclic cavity/ $\pi$-electron conjugation. The macrocycles Co"HMTAA-14 and Co"HMTAA-16 and their nanocomposites with highly conductive carbon black were prepared by a microwave-assisted method and characterized by using multiple spectroscopy techniques. Comparative redox and oxygen reduction activity studies of CO"HMTAA-14 and CO"HMTAA-16 were undertaken by using cyclic voltammetry and linear sweep voltammetry in an alkaline medium. The composite Co"HMTAA-16@C showed good ORR activity compared to Co"HMTAA-14@C in $\mathrm{O}_{2}$-saturated $\mathrm{KOH}$ electrolyte. Since the CO"HMTAA-14 and CO"HMTAA-16 systems have a similar central atom and substituents, the shift of the ORR peak position in the +ive potential region for HMTAA-16 can be attributed to the difference in the size of the macrocyclic cavity (macrocyclic effect) and the extra stability of HMTAA-16 annulene due to its aromaticity.
\end{abstract}

\section{Introduction}

Fuel cells have been developed to offer a more efficient way for energy conversion with the minimum $\mathrm{CO}_{2}$ emissions and a harmless by-product, namely water. But the fuel cell devices suffer from efficiency loss in cathode over-potential. Therefore, it has become necessary to develop high-performance cathode electro-catalysts that are capable of reducing efficiency loss of the cathode over-potential. Platinum derived catalysts were identified as the most promising catalysts in fuel cell devices. ${ }^{1}$ But Pt-based electro-catalysts have serious limitations including poor abundance, high-priced cost, and low viable accessibility, which have restricted the application of Pt-based electrocatalysts for marketable uses. Consequently, seeking a new potential alternative of Pt-based catalysts has become an apparent aim. ${ }^{2}$ Macrocyclic complexes have been largely considered as alternatives for Pt-based ORR catalysts. ${ }^{3}$ But the major challenges are (i) to understand the parameters of macrocycles like the macrocyclic, $\pi$-conjugation, central metal, and substituent effects and their effect on ORR electro-catalysis and

\footnotetext{
${ }^{a}$ Beijing University of Chemical Technology, Beijing, China-100096

${ }^{b}$ Department of Chemistry, GLA University, Mathura, UP-281406, India. E-mail: vinod. vashistha@gla.ac.in
}

† Electronic supplementary information (ESI) available. See DOI: 10.1039/c9ra02169h (ii) the use of macrocycles on the electrode surface for the retention of ORR activity; ${ }^{\mathbf{4 - 9}}$ principally because of the poor stability of these macrocycles in the electrolytic environment. ${ }^{\mathbf{1 0 , 1 1}}$ We are mainly interested in $\mathrm{N}_{4}$-type tetraazaannulene (TAA) macrocycles. The TAA macrocyclic frameworks have a smaller macrocyclic cavity than those of other $\mathrm{N}_{4}$ type macrocycles such as porphyrins and phthalocyanines. The main advantage of these small macrocycles is that the electron density of these macrocycles can be increased on the electrode surface. Furthermore, the macrocyclic cavity size, $\pi$-conjugation, central metal, and substituents can have strong electronic effects on the active sites for ORR. This indicates that the ORR activity of TAA macrocycles might be enhanced by altering these macrocyclic parameters. $^{12}$ The hexamethyl substituted TAA macrocycles like HMTAA-14 and HMTAA-16 macrocyclic ligands have been used as mimicking agents, electrocatalysts, and photocatalysts such as in naturally occurring systems of porphyrins and corrin rings. ${ }^{13}$ These macrocycles have the affinity to enable multiple $1 \mathrm{e}^{-}$oxidation routes. Therefore, many tetraazamacrocyclic ligands and their metal complexes have been considered in the quest of finding their applications in electrocatalysis. HMTAA-14, HMTAA-16, and porphyrin ligands all have four co-planar donor sites through the $\mathrm{N}$-atom and form the corresponding dianions on deprotonation. ${ }^{\mathbf{1 4 - 1 6}}$ The HMTAA-14 annulenes are Huckel antiaromatic ( $4 n \pi$ electrons) and flexible, and they can adopt various conformations 
with respect to planarity (known as saddle-shaped). Further, the dianion [HMTAA-14] $]^{2-}$ does not show complete resonance through the entire annulene framework but the $\pi$-electron delocalization remains confined to the 1,3-diiminato linkages. In a similar fashion, HMTAA-16 and porphyrin type annulenes showed complete $\pi$-electron delocalization spread over the entire ligand framework. For HMTAA macrocycles, the stability was also controlled by the size of the macrocyclic ring; a larger macrocyclic ring leads to greater complex stabilization for small metal ions, while larger metal ions show progressively greater complex destabilization with the larger aromatic macrocyclic ring, displaying selectivity towards metal ions that fit best into it. The computational studies suggested that the TAA macrocyclic ligand in the process of activation and binding of molecular oxygen with a Mn metal ion, leading to the formation of $\mathrm{MnN}_{4}-\mathrm{O}_{2}$ adducts, shown to have good ORR activity. ${ }^{17}$ In addition, the $\mathrm{Co}^{\mathrm{II}} \mathrm{TAA}$ macrocyclic complex is more active for ORR compared to cobalt phthalocyanine, catalyzing the reduction of $\mathrm{O}_{2}$ to $\mathrm{H}_{2} \mathrm{O}_{2}$ at potentials $400 \mathrm{mV}$ more positive than that required using $\mathrm{Co}^{\mathrm{II}} \mathrm{TAA},{ }^{18}$ with comparable performance to platinum in the ORR. These efforts inspired us to make an experimental assessment on the studies of ORR activities of CoHMTAA-14/16 macrocycles and the effect of macrocyclic cavity size on their ORR activity, which was not conducted to date. Further, we investigated the redox property and ORR activity of CoHMTAA-14/16 ligated by HMTAA under alkaline conditions and discussed the effect of the ligand structures on the electrochemical behavior and ORR electrocatalysis of CoHMTAA by emphasizing the macrocyclic parameters such as $\pi$-electron conjugation, size of the macrocyclic framework and aromaticity effect on their electrocatalytic ORR activity.

\section{Results and discussion}

\subsection{Morphology and structural characterization of the composites}

The macrocycles and their composites, Co ${ }^{\mathrm{II}}$ HMTAA-14/16 and Co ${ }^{\mathrm{II} H M T A A-14 / 16 @ C,}$ respectively, were synthesized via

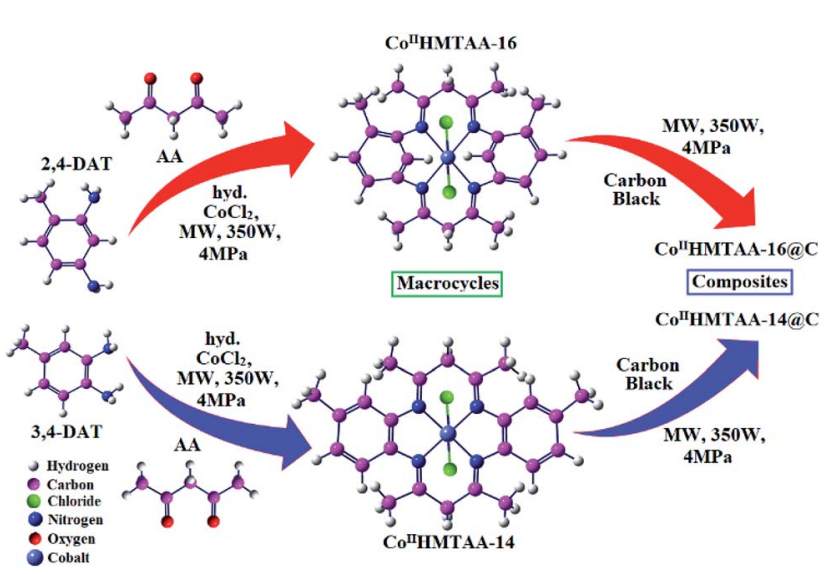

Fig. 1 A systematic schematic diagram of the synthesis of Co"HMTAA-14/16 macrocycles and Co"HMTAA-14/16@C composites. a microwave (MW) assisted method ${ }^{\mathbf{1 9 , 2 0}}$ (see ESI for details $\dagger$ ), as illustrated in Fig. 1.

2.1.1. Fourier transform infrared (FT-IR) spectroscopy studies. The FT-IR study was employed to confirm the structural features of the HMTAA macrocycles. The IR spectra of both HMTAA-14/16 macrocycles and their nanocomposites (Fig. S1 and $\mathrm{S} 2 \dagger$ ) showed the disappearance of the free keto group (near $1700 \mathrm{~cm}^{-1}$ ) and free amino group (near $3300 \mathrm{~cm}^{-1}$ ) and the emergence of new sharp absorption peaks near 1570$1595 \mathrm{~cm}^{-1}$, which verify the reaction between amine and ketone groups to form the "macrocyclic Schiff base", as these peaks may be assigned to $\nu(\mathrm{C}=\mathrm{N})$ stretching vibrations. Further, the absorption bands between 1450 and $1480 \mathrm{~cm}^{-1}$ can be assigned to $\nu(\mathrm{C}=\mathrm{C})$ stretching vibrations of the aromatic moiety. The medium intensity bands appearing from 2800 to $2950 \mathrm{~cm}^{-1}$ can be assigned to the $\nu(\mathrm{C}-\mathrm{H})$ stretch of the methyl groups. In addition, the far infrared spectra displayed some bands near $450-525 \mathrm{~cm}^{-1}$ corresponding to $\nu(\mathrm{M}-\mathrm{N})$ vibrations, and these bands originate from $(\mathrm{M}-\mathrm{N})-\mathrm{C}=\mathrm{N}-$ vibrational modes, which indicates the coordination of the azomethine nitrogen. In the case of their nanocomposites, some minor shifting was observed towards higher wavenumbers, which may be due to some carbon black interaction. ${ }^{21,22}$

2.1.2. Ultraviolet-visible (UV-vis) spectroscopic studies. The UV-vis studies were performed to confirm the electronic environment, the geometry of the macrocycle and the interaction between carbon black and the macrocycles. The UV-vis spectra (Fig. S3a and S4a $\dagger$ ) of both macrocycles were recorded in methanol $\left(10^{-3} \mathrm{M}\right)$ in the range of $200-800 \mathrm{~nm}$. The absorption bands at 253 and $270 \mathrm{~nm}$ may be allocated to the $\pi \rightarrow \pi^{*}$ and $\mathrm{n}$ $\rightarrow \pi^{*}$ electronic transitions, correspondingly. Both macrocycles

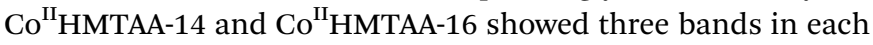
case at (315 nm) $31746 \mathrm{~cm}^{-1},(352 \mathrm{~nm}) 28409 \mathrm{~cm}^{-1}$ and (425 $\mathrm{nm}) 23529 \mathrm{~cm}^{-1}$, and $(315 \mathrm{~nm}) 31746 \mathrm{~cm}^{-1}$, (370 nm) $27027 \mathrm{~cm}^{-1}$ and (460 nm) $21739 \mathrm{~cm}^{-1}$, respectively, and these bands can be attributed to ${ }^{4} \mathrm{~T}_{1 \mathrm{~g}}(\mathrm{~F}) \rightarrow{ }^{4} \mathrm{~A}_{2 \mathrm{~g}}(\mathrm{~F}),{ }^{4} \mathrm{~T}_{1 \mathrm{~g}}(\mathrm{~F}) \rightarrow{ }^{4} \mathrm{~T}_{2 \mathrm{~g}}(\mathrm{~F})$ and ${ }^{4} \mathrm{~T}_{1 \mathrm{~g}}(\mathrm{~F}) \rightarrow{ }^{4} \mathrm{~T}_{1 \mathrm{~g}}(\mathrm{P})$ electronic transitions. Thus, these electronic spectral data are in agreement with the molar conductance data, confirming the octahedral geometry of these macrocycles with axial chloride ions. In addition, the UV-vis spectra of Co ${ }^{\mathrm{II}} \mathrm{HMTAA}-14 @ \mathrm{C}$ and Co ${ }^{\mathrm{II}} \mathrm{HMTAA}-16 @ \mathrm{C}$ (Fig. S3b and $\mathrm{S} 4 \mathrm{~b} \dagger$ ) were quite different as they showed a bathochromic shift in the main absorption bands, which confirmed the adsorption of these macrocycles via $\pi-\pi$ interactions. This clearly indicates the strong electronic coupling between $\mathrm{Co}^{\mathrm{II}} \mathrm{HMTAA}-14 / 16$ and the carbon support. ${ }^{23,24}$

2.1.3. Mass spectra. The mass spectra, recorded in positive mode for both macrocycles, showed a more intense peak at $\mathrm{m} / \mathrm{z}$ 502 that corresponds to the molecular ion peak $(\mathrm{M})^{+}$, which is in good agreement with respect to the molecular formula (Fig. S4 $\dagger$ ). The other observed peaks at $m / z 443,175,134$ and 71 can be assigned to other different cleavage moieties. ${ }^{13,25}$

2.1.4. X-ray photoelectron spectroscopy (XPS) studies. The XPS studies were undertaken to characterize the chemical composition of the composites. The XPS spectra of N1s (Fig. 2a) of HMTAA-14@C showed two peaks at around $399.70 \mathrm{eV}$ and $400.10 \mathrm{eV}$, which may be due to the presence of $\mathrm{C}-\mathrm{N}$ and $\mathrm{C}=\mathrm{N}$, 
(a)

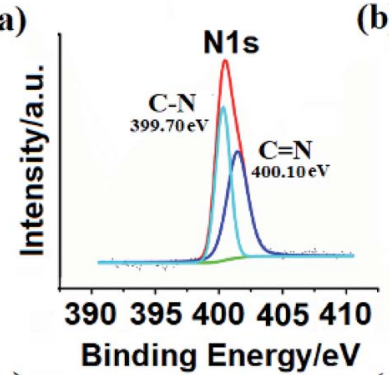

(c)

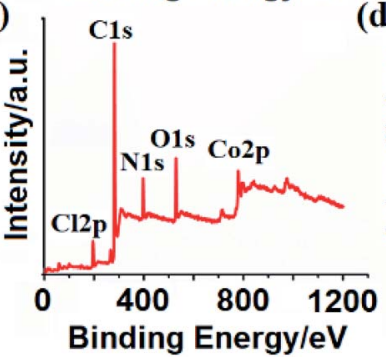

(b)

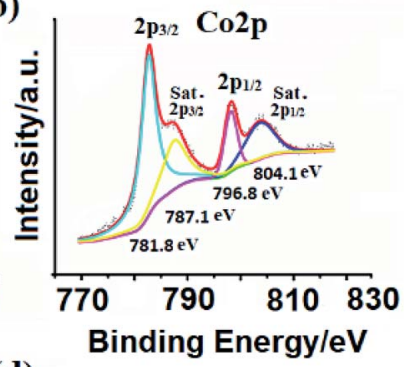

d)

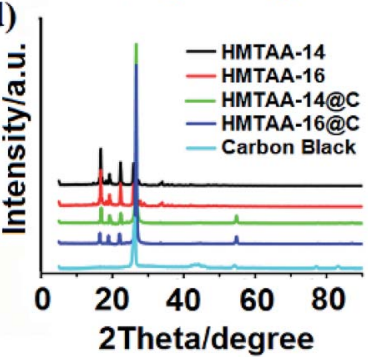

Fig. 2 XPS spectra of HMTAA-16: (a) N1s, (b) Co2p, and (c) survey; and (d) XRD patterns

respectively. From the literature, it is clear that $\mathrm{Co}(\mathrm{II})$ and $\mathrm{Co}(\mathrm{III})$ have comparative $2 \mathrm{p}$ binding energies however they can be separated by the $\operatorname{Co} 2 \mathrm{p}_{1 / 2}$ and $\operatorname{Co} 2 \mathrm{p}_{3 / 2}$ full width at half maximum for high-turn $\mathrm{Co}$ (II) and low-turn $\mathrm{Co}$ (III). A fine probe of Co2p (Fig. 2b) presented four peaks at 781.8, 787.1 (for Co2 $\mathrm{p}_{3}$ / $2)$, 796.8, and $804.1 \mathrm{eV}\left(\mathrm{Co} 2 \mathrm{p}_{1 / 2}\right)$, indicating that Co2p demonstrates the $2+/ 3+$ oxidation state of Co during the photoreduction of HMTAA-14 by X-rays. ${ }^{26}$ Further, the XPS survey (Fig. 2c) for HMTAA-14 is in good agreement with the elemental composition, showing characteristics of Cl2p ( 199.0 eV), N1s ( $\sim 400.0 \mathrm{eV})$, O1s $(\sim 530 \mathrm{eV})$ and Co2p $(\sim 779 \mathrm{eV}) .{ }^{27}$ Thus, the XPS studies further confirmed the composite compositions in accordance with the proposed structural features of the catalysts.

2.1.5. X-ray diffraction (XRD) studies. The structural features of the macrocycles were characterized using XRD. Fig. 2d shows the XRD patterns of carbon black and the composites HMTAA-14/16@C, and the inset shows the XRD patterns of the unsupported HMTAA-14/16 macrocycles. The unsupported HMTAA-14/16 showed sharp characteristic diffraction peaks at $c a$. 7-20 and the composites HMTAA-14/ 16@C also showed a similar pattern, which can be attributed to the aggregation of HMTAA-14/16 macrocycles on carbon black. The observed external intense peak at ca. 26 in each pattern of HMTAA-14/16@C can be assigned to the characteristic carbon black diffraction peak, ${ }^{28}$ indicating the graphitic structure of carbon black. In comparison to that of pure carbon black, the XRD peak of graphitic carbon in the composites HMTAA-14@C and HMTAA-16 shifted toward a higher degree, which can be attributed to the expansion of carbon black during the modification using microwave irradiation. ${ }^{29}$

2.1.6. Transmission electron microscopy (TEM) study. The morphological study of the synthesized composites was performed using TEM. The typical TEM images of the composite

HMTAA-16@C showed the "particle aggregation morphology" of the carbon black (Fig. 3). However, no individual HMTAA-16 was observed in this composite. This indicates that the use of high surface area carbon black as a supporting material inhibits the pi-pi-stacking of the HMTAA-14 molecule; as a result, a core-shell structured composite where the HMTAA-14 molecule is adsorbed on the carbon black material is formed.$^{30}$ Our results are in accordance with the previously reported similar work on an iron phthalocyanine composite, FePc@C. ${ }^{31}$

\section{Electrochemical measurements}

\subsection{Redox studies of Co ${ }^{\mathrm{II}} \mathrm{HMTAA-14}$ and Co ${ }^{\mathrm{II}} \mathrm{HMTAA-16}$}

The cyclic voltammograms (CVs) of both $\mathrm{Co}^{\mathrm{II}} \mathrm{HMTAA}-14$ and

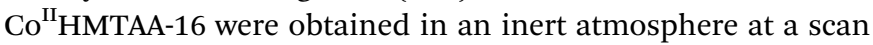
rate of $50 \mathrm{mV} \mathrm{s}^{-1}$. The macrocycles Co ${ }^{\mathrm{II}} \mathrm{HMTAA}-14$ and Co ${ }^{\mathrm{II} H M T A A}-16$ showed similar redox behavior with a slight difference in the anodic peak potential $\left(E_{\mathrm{p}, \mathrm{a}}\right)$ and cathodic peak potential $\left(E_{\mathrm{p}, \mathrm{c}}\right)$ peak positions. The CVs of both $\mathrm{Co}^{\mathrm{II}} \mathrm{HMTAA}-14$ and Co ${ }^{\mathrm{II}} \mathrm{HMTAA}-16$ (Fig. $4 \mathrm{a}$ and b) showed first redox couples at $+0.76 \mathrm{~V}$ and $+0.81 \mathrm{~V}$ corresponding to $\mathrm{Co}^{3+} / \mathrm{Co}^{2+}$ and the second redox couple at $+1.09 \mathrm{~V}$ and $+1.13 \mathrm{~V}$ corresponding to $\mathrm{L}^{+} /$ $\mathrm{L}^{0}\left(\mathrm{~L}=\right.$ HMTAA), respectively. ${ }^{31,32}$ In addition, based on the peak separation $\left(\Delta E_{\mathrm{p}}=E_{\mathrm{p}, \mathrm{a}}-E_{\mathrm{p}, \mathrm{c}}\right)$, which was observed to be near to $+60 \mathrm{mV}$, and peak current ratio $\left(i_{\mathrm{p}, \mathrm{a}} / i_{\mathrm{p}, \mathrm{c}}\right)$ near to 0.81 (in both cases), a quasi-reversible process may be assigned to the $\mathrm{Co}^{3+} /$ $\mathrm{Co}^{2+}$ redox couple. Further, the anodic and cathodic peak potentials were observed to be independent of scan rate (Fig. 4c) when the scan rate was varied from $25 \mathrm{mV} \mathrm{s}^{-1}$ to $500 \mathrm{mV} \mathrm{s}^{-1}$, and the plots of $i_{\mathrm{p}} v s . v^{1 / 2}$ (inset Fig. 3c) were found to be linear and follow the "Randles-Sevcik" equation ${ }^{13,34,35}$

$$
i=2.69 \times 10^{5} n^{3 / 2} A D^{1 / 2} c v^{1 / 2}
$$

where $n$, number of electrons transferred; $A$, area of the electrode; $D$, diffusion coefficient; $c$, analyte concentration; $v$, scan rate.

Since both the Co ${ }^{\mathrm{II}} \mathrm{HMTAA}-14$ and $\mathrm{Co}^{\mathrm{II}} \mathrm{HMTAA}-16$ macrocycles have similar substituents, the difference in the shifting of peak position in the +ive potential region of the $\mathrm{Co}^{\mathrm{II}} \mathrm{HMTAA}-16$ macrocyclic complex can be attributed to the difference in the macrocyclic cavity size/extent of unsaturation and extra stability as aromaticity of the Co ${ }^{\mathrm{II}} \mathrm{HMTAA}-16$ complex. ${ }^{33} \mathrm{Next}$, we studied
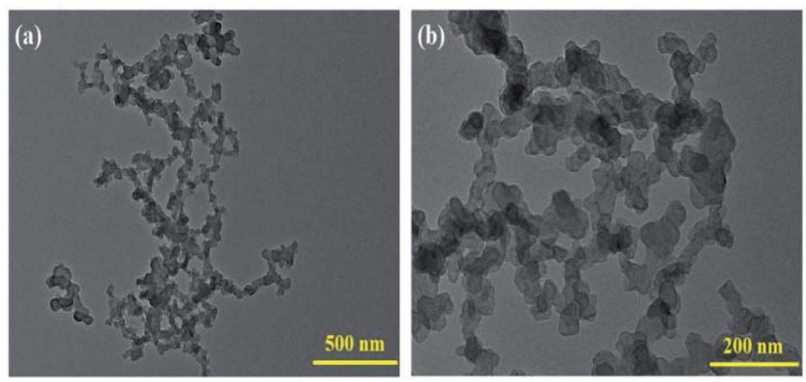

Fig. 3 TEM images of HMTAA-16: (a) low magnification and (b) high magnification. 

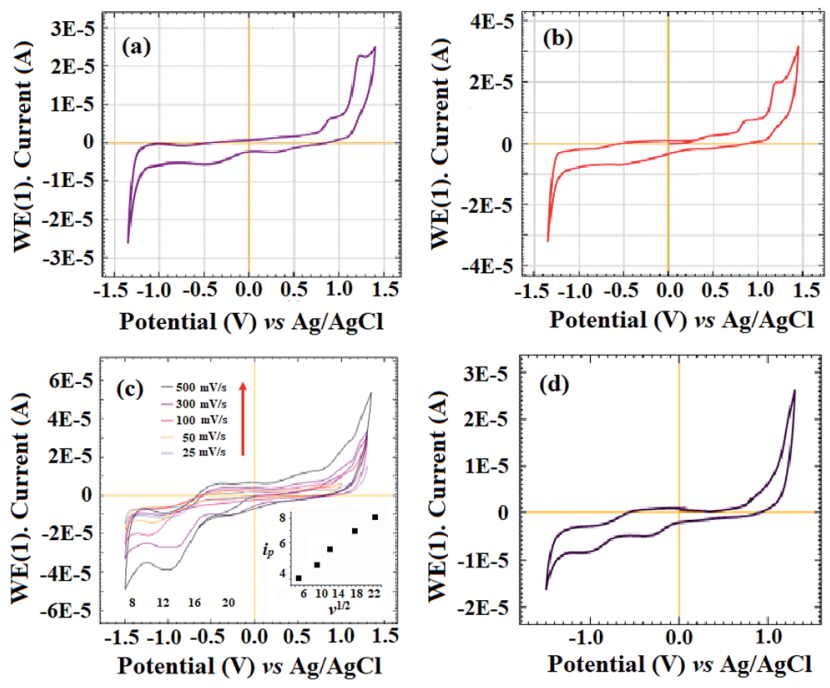

Fig. 4 CVs of (a) Co"HMTAA-14 and (b) Co"HMTAA-16, (c) a cyclic voltammogram of Co"HMTAA-14 at varying scan rates and (d) a cyclic voltammogram of Co"HMTAA-14 in the presence of pyridine.

the axial ligation effect on the nature of electrochemistry of the planar $\mathrm{N}_{4}$ chelates of the macrocycles by using pyridine as a strong axial ligand donor. ${ }^{30,32-35}$ Fig. $4 d$ shows the considerable effect of the addition of a small amount of pyridine on the voltammetry of $\mathrm{Co}^{\mathrm{II}} \mathrm{HMTAA}-14$ by eliminating the $\mathrm{Co}^{\mathrm{II}} / \mathrm{Co}^{\mathrm{III}}$ redox couple. Our results are in good agreement with previous published similar analogous Co ${ }^{\mathrm{II}} \mathrm{DPTAA}$ systems. ${ }^{33}$ The observed redox parameters for both macrocycles are given in Table 1.

\subsection{ORR activity of the composites Co ${ }^{\mathrm{II}} \mathrm{HMTAA}-14 @ \mathrm{C}$ and Co'HMTAA-16@C}

The CVs of Co ${ }^{\mathrm{II}} \mathrm{HMTAA}-14 @ \mathrm{C}, \mathrm{Co}^{\mathrm{II}} \mathrm{HMTAA}-16 @ \mathrm{C}$ and 20\% Pt/C (Fig. 5a) were recorded in $\mathrm{O}_{2}$-saturated $0.1 \mathrm{M} \mathrm{KOH}$ electrolyte at a scan rate of $50 \mathrm{mV} \mathrm{s}^{-1}$ and with $0.25 \mu \mathrm{g} \mathrm{cm} \mathrm{cm}^{-2}$ loading amounts of each catalyst onto the glassy carbon electrode. The onset potential of Co ${ }^{\mathrm{II}} \mathrm{HMTAA}-14 @ \mathrm{C}, \mathrm{Co}^{\mathrm{II}} \mathrm{HMTAA}-16 @ \mathrm{C}$ and 20\% Pt/ $\mathrm{C}$ was found to be approximately $+0.85 \mathrm{~V},+0.93 \mathrm{~V}$ and $+0.95 \mathrm{~V}$ while the formal potential $\left(E_{1 / 2}\right)$ was observed in the order of Co ${ }^{\mathrm{II} H M T A A @ C ~}\left(E_{1 / 2}=+0.70 \mathrm{~V}\right)<\mathrm{Co}^{\mathrm{II}} \mathrm{HMTAA}-16 @ \mathrm{C}\left(E_{1 / 2}=\right.$ $+0.82 \mathrm{~V})<20 \% \mathrm{Pt} / \mathrm{C}\left(E_{1 / 2}=+0.85 \mathrm{~V}\right) .{ }^{36}$ These results are in good agreement with the corresponding LSV curves (Fig. 5b). Thus, Co ${ }^{\text {II } H M T A A-16 @ C ~ s h o w e d ~ a ~ m o r e ~ p o s i t i v e ~ f o r m a l ~ p o t e n t i a l ~}$

Table 1 Redox data for Co"HMTAA-14 and Co"HMTAA-16 macrocycles observed in DMF containing 0.1 M TEAP and $10^{-3} \mathrm{M}$ concentrations of each complex at a scan rate $25 \mathrm{mV} \mathrm{s}^{-1}$

\begin{tabular}{|c|c|c|}
\hline Macrocycle & $\mathrm{Co}^{2+/ 3+}$ & HMTAA $^{+/ 0}$ \\
\hline $\mathrm{Co}^{\mathrm{II} H M T A A-14}$ & $+0.76 \mathrm{~V}$ & $+1.09 \mathrm{~V}$ \\
\hline Co ${ }^{\mathrm{II}} \mathrm{HMTAA}-16$ & $+0.81 \mathrm{~V}$ & $+1.13 \mathrm{~V}$ \\
\hline $\mathrm{Co}^{\mathrm{II}} \mathrm{DPTAA}^{29}$ & $+0.24 \mathrm{~V}$ & $+0.56 \mathrm{~V}$ \\
\hline Co ${ }^{\mathrm{II}} \mathrm{HMTAA}-14+$ excess pyridine & $+0.60 \mathrm{~V}$ & $+0.86 \mathrm{~V}$ \\
\hline Co $^{\mathrm{II}}$ DPTAA-14 + excess pyridine ${ }^{29}$ & $+0.02 \mathrm{~V}$ & $+0.64 \mathrm{~V}$ \\
\hline
\end{tabular}
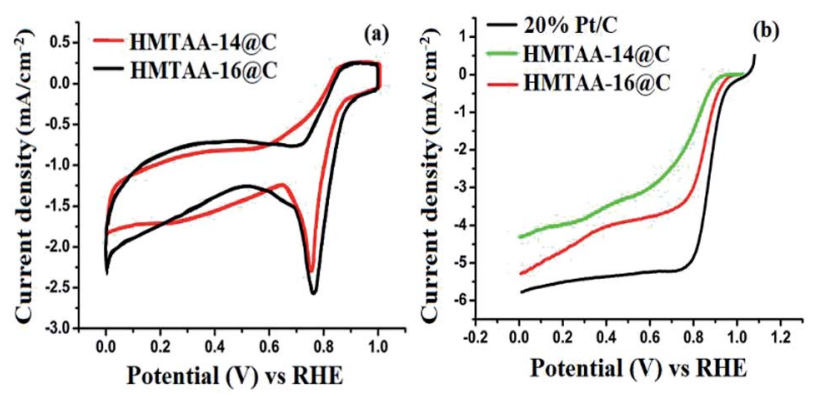

Fig. 5 (a) CVs collected of Co"HMTAA-14@C and Co"HMTAA-16@C, and (b) LSV curves collected of Co"HMTAA-14aC, Co"HMTAA-16@C and $20 \% \mathrm{Pt} / \mathrm{C}$ in $\mathrm{O}_{2}$-saturated $0.1 \mathrm{M} \mathrm{KOH}$ electrolyte at a scan rate of $50 \mathrm{mV} \mathrm{s}^{-1}$ and $5 \mathrm{mV} \mathrm{s}^{-1}$, respectively, at room temperature.

than Co ${ }^{\mathrm{II}} \mathrm{HMTAA}-14 @ \mathrm{C}$, indicating the enhanced ORR performance of Co ${ }^{\mathrm{II}} \mathrm{HMTAA}-16 @ \mathrm{C}$ as compared to $\mathrm{Co}^{\mathrm{II}} \mathrm{HMTAA}-14 @ \mathrm{C}$.

Both composites, Co ${ }^{\mathrm{II}} \mathrm{HMTAA}-14 @ \mathrm{C}$ and Co ${ }^{\mathrm{II}} \mathrm{HMTAA}-16 @ \mathrm{C}$, have a similar chemical composition and carbon support and only differ in the electronic structure inside of the macrocycles. The electrochemistry of the unsupported Co ${ }^{\mathrm{II}} \mathrm{HMTAA}-14$ and Co ${ }^{\mathrm{II} H M T A A-16}$ macrocycles suggested that the difference in redox peak position can be attributed to the different electronic environment.

Similarly, we observed that the ORR catalytic activity varied with the size of the macrocyclic cavity and extent of $\pi$-electron conjugation. $\mathrm{Co}^{\mathrm{II}} \mathrm{HMTAA}-14$ and $\mathrm{Co}^{\mathrm{II}} \mathrm{HMTAA}-16$ macrocyclic frameworks have coplanar $\mathrm{N}_{4}$-donor atom arrangements that can form corresponding dianions on deprotonation. Thus, the protonated HMTAA-14 showed an anti-aromatic nature $(4 n \pi$ electron rule) followed by incomplete resonance through the entire framework; as a result, it showed poor activity and stability towards ORR. Besides, HMTAA-16 is a member of the porphyrin and phthalocyanine family, which have complete $\pi$ electron delocalization over the entire macrocyclic framework followed by an aromatic nature $\left(4 n+2 \pi\right.$ electron rule). ${ }^{7-10,13}$ Thus, this special difference between the antiaromatic and aromatic nature of HMTAA-14 and HMTAA-16, respectively, and macrocyclic effect can explain the higher ORR activity of the Co ${ }^{\mathrm{II}} \mathrm{HMTAA}-16$ as compared to $\mathrm{Co}^{\mathrm{II}} \mathrm{HMTAA}-14$ macrocycle containing composites. ${ }^{37}$ The ORR activity of macrocycles is associated with $\mathrm{e}^{-}$transfer processes that involve the $\pi$-electron conjugation in the macrocycle, d-electrons of the metal center and charge transfer transitions between them. Although these macrocycles show comparable ORR activity with that of $20 \% \mathrm{Pt} /$ $\mathrm{C}$, it seems that their ORR activity can be further improved by tailoring the electronic structure using appropriate substitution and carbon support. Usually, for the $\mathrm{Co}^{\mathrm{II}}-\mathrm{N} 4$ macrocycles, $\mathrm{Co}^{\mathrm{III}}$ is probably not formed upon interaction with the oxygen molecule since the $\mathrm{Co}^{\mathrm{III}} / \mathrm{Co}^{\mathrm{II}}$ formal potential is much more positive, so the $\mathrm{Co}^{\mathrm{II}} / \mathrm{Co}^{\mathrm{I}}$ redox process can be considered as the ORR mediator by providing the Co ${ }^{\mathrm{II}}$ active site for ORR. ${ }^{38}$ The cyclic voltammograms of both Co ${ }^{\mathrm{II}} \mathrm{HMTAA}-14$ and Co ${ }^{\mathrm{II}} \mathrm{HMTAA}-$ 16 showed distinct cathodic peaks near $-0.50 \mathrm{~V}$, and maybe this redox couple played an important role as mediator to catalyze ORR. So, our future intention is to design several excellent 
macrocycle-based ORR electrocatalysts by using different macrocyclic framework sizes, metal ions, electron donating or withdrawing groups and carbon supports to alter their redox potential and electronic structure.

\section{Conclusions}

In the present studies, two macrocycles, $\mathrm{Co}^{\mathrm{II}} \mathrm{HMTAA}-14$ and $\mathrm{CO}^{\mathrm{II}} \mathrm{HMTAA}-16$, were synthesized and characterized by using multiple spectroscopic techniques that confirmed an octahedral geometry for both macrocycles. The cyclic voltammograms of Co ${ }^{\mathrm{II}} \mathrm{HMTAA}-14$ and $\mathrm{Co}^{\mathrm{II}} \mathrm{HMTAA}-16$ showed a considerable difference in the values of $E_{\mathrm{p}, \mathrm{a}}$ and $E_{\mathrm{p}, \mathrm{c}}$. The cyclic voltammogram of $\mathrm{Co}^{\mathrm{II}} \mathrm{HMTAA}-14$ shows two distinct redox couples at $+0.76 \mathrm{~V}$ and $+1.09 \mathrm{~V}$, whereas that of $\mathrm{Co}^{\mathrm{II}} \mathrm{HMTAA}-16$ shows the corresponding redox couples at $+0.81 \mathrm{~V}$ and $+1.13 \mathrm{~V}$, respectively. Since both the $\mathrm{Co}^{\mathrm{II}} \mathrm{HMTAA}-14$ and $\mathrm{Co}^{\mathrm{II}} \mathrm{HMTAA}-16$ complexes have similar substituents, the difference in the shifting of peak position in the +ive potential region of the

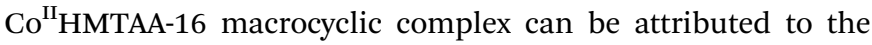
difference in the size of the macrocyclic cavity or the extent of unsaturation and extra stability in terms of the aromaticity of HMTAA-16 annulene. Similarly, the ORR activities of their composites could be correlated and it was concluded that the external stability of HMTAA-16 annulene can play a key role in enhancing the ORR activity of $\mathrm{Co}^{\mathrm{II}} \mathrm{HMTAA}-16$ macrocycle based electrocatalysts as compared to antiaromatic or nonaromatic systems. Further, the present work can be further explored to design macrocycle-based electrocatalysts for various electrocatalytic processes.

\section{Conflicts of interest}

There are no conflicts to declare.

\section{Acknowledgements}

We are thankful to GLA University, Mathura and IIT Roorkee, Roorkee for infrastructural support, and SAIF Panjab University Chandigarh and Beijing University of Chemical Technology, China for aiding in completion of the studies.

\section{References}

1 S. Walch, A. Dhanda, M. Aryanpour and H. Pitsch, J. Phys. Chem. C, 2008, 112, 831.

2 C. H. Tsai, C. J. Shih, W. S. Wang, W. F. Chi, W. C. Huang, Y. C. Hu and Y. H. Yu, Appl. Surf. Sci., 2018, 434, 414.

3 Y. Liu, Y. Y. Wu, G. J. Lv, T. Pu, X. Q. He and L. L. Cui, Electrochim. Acta, 2013, 112, 269.

4 Y. Zhao, H. Tang, N. Yang and D. Wang, Adv. Sci., 2018, 5, 1800959.

5 Y. Zhao, J. Wan, H. Yao, L. Zhang, K. Lin, L. Wang, N. Yang, D. Liu, L. Song, J. Zhu, L. Gu, L. Liu, H. Zhao, Y. Li and D. Wang, Nat. Chem., 2018, 10, 924.

6 Y. Zhao, L. Zhang, J. Qi, Q. Jin, K. Lin and D. Wang, Acta Phys.-Chim. Sin., 2018, 34, 1048.
7 N. Parvin, Q. Jin, Y. Wei, R. Yu, B. Zheng, L. Huang, Y. Zhang, L. Wang, H. Zhang, M. Gao, H. Zhao, W. Hu, Y. Li and D. Wang, Adv. Mater., 2017, 29(18), 1606755.

8 H. Tang, J. Wang, H. Yin, H. Zhao, D. Wang and Z. Tang, Adv. Mater., 2015, 27, 1117.

9 H. Tang, C. M. Hessel, J. Wang, N. Yang, R. Yu, H. Zhaod and D. Wang, Chem. Soc. Rev., 2014, 43, 4281.

10 K. Wiesener, D. Ohms, V. Neumann and R. Franke, Mater. Chem. Phys., 1989, 22, 457.

11 J. H. Zagala, F. J. Recio, C. A. Gutierrez, C. Zuñiga, M. A. Páez and C. A. Caro, Electrochem. Commun., 2014, 41, 24.

12 P. Gouérec, A. Biloul, O. Contamin, G. Scarbeck, M. Savy, J. Riga, L. T. Wengand and P. Bertrand, J. Electroanal. Chem., 1997, 422, 61.

13 Á. R. Escudero, G. L. Estiú, J. Costamagna and G. I. C. Jirón, J. Coord. Chem., 2003, 56, 1257.

14 J. F. M. Oth, H. Baumann, J. M. Giles and G. Schroeder, J. Am. Chem. Soc., 1972, 94, 3498.

15 J. F. M. Oth, G. Anthoine and J. M. Gilles, Tetrahedron Lett., 1968, 9, 6265.

16 F. L. Hirshfeld and D. Rabinovich, Acta Crystallogr., 2010, 19, 235.

17 A. Costa, A. Luís, P. Silva, R. B. Viana, A. A. Tanaka, J. de Jesus and G. Varela Jr, J. Mol. Model., 2016, 22, 217.

18 A. Putten, A. Elzing, W. Visscher and E. Barendrecht, J. Electroanal. Chem. Interfacial Electrochem., 1987, 221, 95.

19 A. R. Cutler and D. Dolphin, J. Coord. Chem., 1976, 6, 59.

20 K. Sakata, Y. Saitoh, K. Kawakami, N. Nakamura, T. Hori, Y. Nakano and M. Hashimoto, Synth. React. Inorg., Met.Org., Nano-Met. Chem., 2006, 26, 1267.

21 R. Sustmann, H. G. Korth, D. Kobus, J. Baute, K. H. Seiffert, E. Verheggen, E. Bill, M. Kirsch and H. Groot, Inorg. Chem., 2007, 46, 11416.

22 M. A. Ali, A. H. Mirza, A. M. S. Hossain and M. Nazimuddin, Polyhedron, 2001, 20, 1045.

23 K. Sakata, H. Shibata, M. Hashimoto and A. Tsuge, J. Coord. Chem., 2002, 55, 15.

24 K. Sakata and T. Hori, Synth. React. Inorg., Met.-Org., NanoMet. Chem., 1990, 20, 263.

25 D. P. Singh, R. Kumar, M. Kamboj and K. Jain, J. Coord. Chem., 2009, 62, 2995.

26 J. Stoch and A. Capecki, Surf. Interface Anal., 1990, 15, 206.

27 L. Xuguang, X. Wei, L. Tianhong, J. Yiping, L. Hongying and S. Yun, Chem. Res. Chin. Univ., 2003, 24, 1246.

28 K. Sakata, Z. Wang, M. Hashimoto, A. Tsuge and Y. Tanoue, Synth. React. Inorg., Met.-Org., Nano-Met. Chem., 1999, 29, 265.

29 H. Shang, Y. Lu, F. Zhao, C. Chao, B. Zhang and H. Zhang, RSC Adv., 2015, 5, 75728.

30 Y. Yuan, J. Ahmed and S. Kim, J. Power Sources, 2011, 196, 1103.

31 S. Zhang, H. Zhang, X. Hua and S. Chen, J. Mater. Chem. A, 2015, 3, 10013.

32 V. B. Rana, P. Singh, D. P. Singh and M. P. Teotia, Transition Met. Chem., 1982, 7, 174.

33 B. D. Alexander, J. A. Crayston and T. J. Dines, J. Electroanal. Chem., 2007, 605, 109. 
34 A. Deronzier and M. J. Marques, Electrochim. Acta, 1994, 39, 1377.

35 S. Karunakaran and M. Kandaswamy, Dalton Trans., 1994, 10, 1595.

36 K. Liu, Y. Lei, R. Chen and G. Wang, Oxygen Electroreduction on $\mathrm{M}^{-\mathrm{N}_{4}}$ Macrocyclic Complexes,
Electrochemistry of $\mathrm{N}_{4}$ Macrocyclic Metal Complexes, 2nd edn, 2016.

37 J. H. Cameron and S. Graham, Dalton Trans., 1992, 3, 385.

38 J. H. Zagal, S. Griveau, J. F. Silva, T. Nyokong and F. Bedioui, Coord. Chem. Rev., 2010, 254, 2755. 